\title{
A Rare Case of Fracture of Radius Associated with Dislocation of Both Distal and Proximal Radio-Ulnar Joint
}

\author{
Paragjyoti Gogoi ${ }^{1}$, Anshuman Dutta ${ }^{1}$, Arup Kumar Daolagupu ${ }^{1}$, Arun Kumar Sipani ${ }^{1}$, \\ Prasanta Sonowal ${ }^{2}$ \\ ${ }^{1}$ Department of Orthopaedics \& Trauma, Silchar Medical College, Silchar, India \\ ${ }^{2}$ Department of Anaesthesiology, Silchar Medical College, Silchar, India \\ Email: pggogoiparag@gmail.com
}

Received 12 April 2014; revised 10 May 2014; accepted 8 June 2014

Copyright (C) 2014 by authors and Scientific Research Publishing Inc.

This work is licensed under the Creative Commons Attribution International License (CC BY).

http://creativecommons.org/licenses/by/4.0/

c) (i) Open Access

\begin{abstract}
Single bone forearm fractures are usually associated with dislocation of one radio-ulnar joint. The association of ulnar fractures with dislocation of proximal radio-ulnar joint and radius fractures with distal radio-ulnar joint is well described. Classically they are better known as Monteggia and Galeazzi fracture dislocations respectively. These peculiar presentations are attributed to intricate relationship of the forearm bones joined together as a unit by two radio-ulnar joints at proximal and distal ends and the interosseous membrane in the middle part. However, simultaneous dislocation of the both radio-ulnar joints associated with fracture of single bone is a very rare event. Literature search does not reveal a single case of such type. We are presenting here a case of fracture shaft of radius associated with dislocation of both proximal and distal radio-ulnar joints. The patient was managed by open reduction and fixation of the radius by a compression plate and the dislocations were reduced by closed method and stabilized with small $\mathrm{K}$ wires.
\end{abstract}

\section{Keywords}

Forearm Bones, Monteggia Fracture, Galeazzi Fracture, DRUJ, Proximal Radio-Ulnar Joint

\section{Introduction}

Forearm bones along with two radio-ulnar joints and intervening interosseous membrane works as a single functional unit. The radio-ulnar joints and the interosseous membrane moving simultaneously result in supination and pronation movement which add to the dexterity of the upper limb. Disruption of any of these components 
result in great loss of supination-pronation movement thereby causing impaired function of the limb. Commonly found fractures of the both bone usually do not associated with injury to these components. However, single bone fracture resulting mainly from indirect force always disrupts these articulations. Thus in Galeazzi fracture shaft of the radius fracture is associated with dislocation of the distal radio-ulnar joint and similarly in Monteggia fracture the shaft of ulna fracture are found with dislocation of the proximal radio-ulnar joint [1] [2]. These are commonly found and well studied fracture dislocations of forearm. Galeazzi fracture dislocations are about three times more common than Monteggia fracture dislocation and together they comprise $5 \%$ to $8 \%$ of all forearm fractures [3] [4].

Many variant of these fracture dislocations are described in [5] [6]. We recently encountered a very peculiar fracture of radius which we felt worth reporting wherein the fracture of the shaft of the radius is associated with dislocation of both proximal and distal radio-ulnar joints. We searched the English literature but failed to notice similar fracture dislocation, maybe this is the first case of this kind.

\section{The Case Report}

A 25 years old man attended our casualty department with a history of injury to his left forearm following bike accident. He was riding a bike which hit a post and he was thrown from the vehicle and landed over his left hand. He felt an immediate pop and unable to move his left elbow and wrist and was associated with extreme pain. The forearm started swelling, however there was no external bleeding. He attended our casualty after half an hour after the accident and was evaluated immediately and thoroughly. He had his vital parameters within normal limits except mildly elevated blood pressure and tachycardia. Head injury and other possible injuries to thorax and abdomen were ruled out. On examination the left forearm was swollen and extremely painful on movement. Elbow and wrist movement was restricted and painful. Distal radial artery pulsation was palpable and both sensory and motor functions of the hand were normal. Slight abrasion was noted over volar aspect of hand and the forearm skin cover was intact.

$\mathrm{X}$-ray of the forearm showed a very unusual picture (Figure 1). The radius has got a fracture at the midshaft and both the proximal and distal radio-ulnar joints were dislocated. The ulna was found without any obvious deformity or fracture. In orthopaedic terms it has a Galeazzi fracture dislocation combined with dislocation of proximal radio-ulnar joint.

The left upper limb was immobilized and investigated for pre-operative evaluation; all came out to be within normal limits.

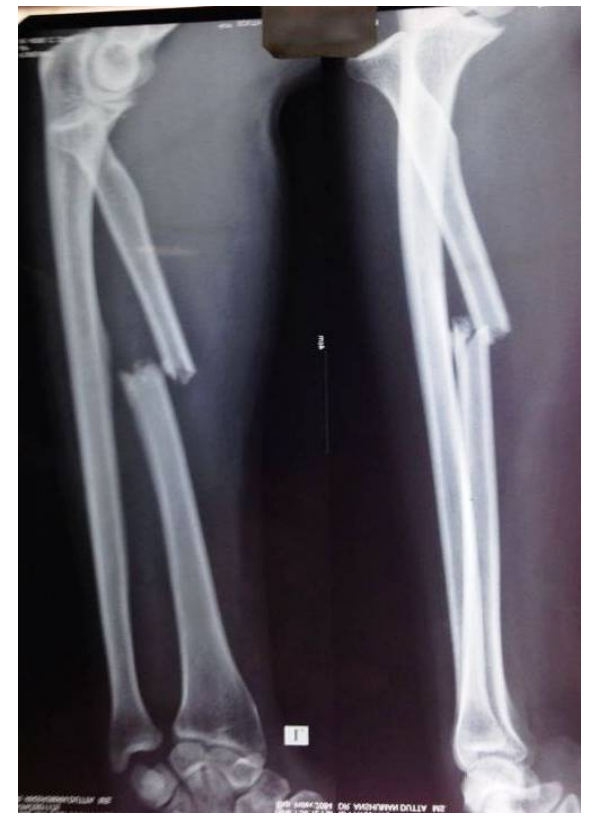

Figure 1. Preoperative X-ray showing dislocation of both distal and proximal radio-ulnar joint along with fracture shaft of radius. 
The patient was taken for open reduction and internal fixation of the radial shaft fracture and closed/open reduction of the radio-ulnar joints. The radius fracture was addressed by anterior Henry's approach. The fracture was exposed, cleaned and fixed with a seven holes small DCP with three 3 - $5 \mathrm{~mm}$ screws on either side of fracture. The interosseous membrane near the fracture site was found disrupted and the exact extent could not be ascertained. After fixation of the fracture the elbow and wrist were examined under image intensifier. The DRUJ seemed reduced but, proximally the radial head was clearly out of the joint. With traction it was possible to reduce the radial head into normal position which was confirmed in IITV picture, but was unstable. The proximal radio-ulnar joint was first stabilized with a $2 \mathrm{~mm} \mathrm{~K}$-wire inserted from distal humerus into radial head keeping the elbow flexed to 90 degrees (Figure 2) and then the DRUJ was stabilized with another $2 \mathrm{~mm} \mathrm{~K}$-wire from Ulna to Radius keeping the forarm in supination (Figure 3 and Figure 4). The K-wires were bent and kept outside for later easy removal for mobilization (Figure 5). No attempt was made to repair the TFCC as the DRUJ seemed stable under fluoroscopy.

Post-operative X-rays confirmed the reduction of both the joints as well as the fracture (Figure 6). Immobilization of the forearm in this fixed position was continued for three weeks and then only wrist flexion and extension started but no rotational movement was allowed. At six weeks, the K-wires were removed and gentle mobilization of the forearm started with elbow physiotherapy.

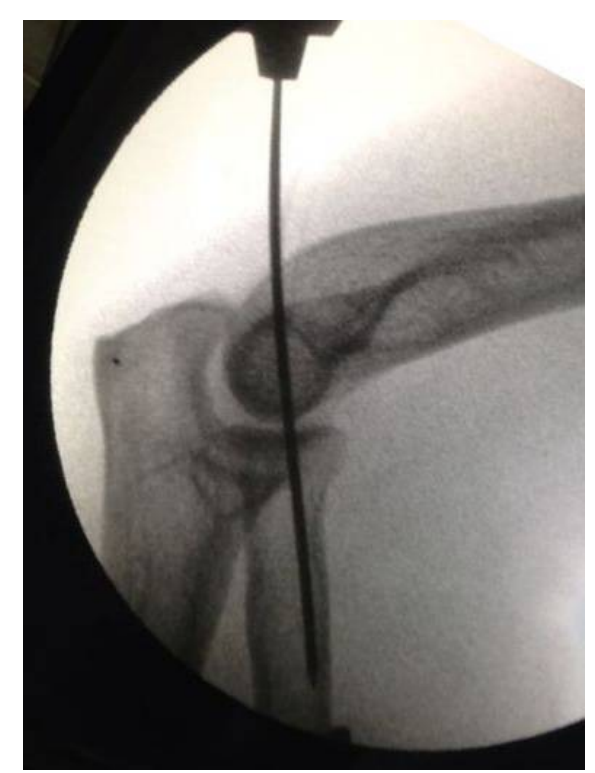

Figure 2. Per-operative fixation of Proximal Radio-ulnar joint.

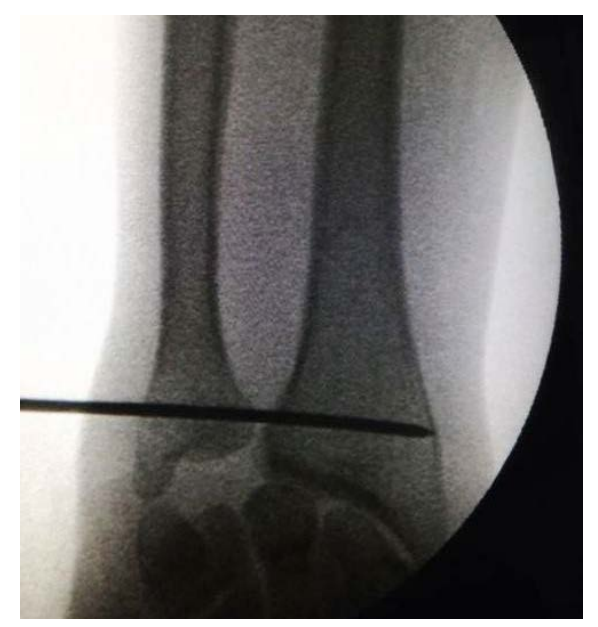

Figure 3. Per-operative fixation of Distal Radio-Ulnar joint. 


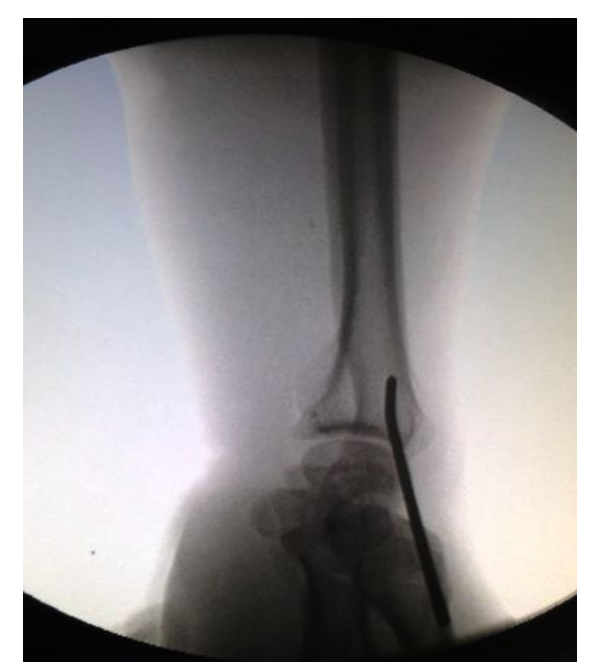

Figure 4. Per-operative fixation of Distal Radio-Ulnar joint.

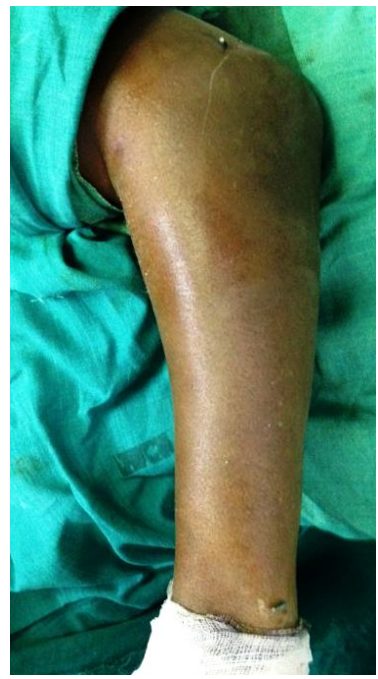

Figure 5. Post-operative picture showing percutaneous K-wires.
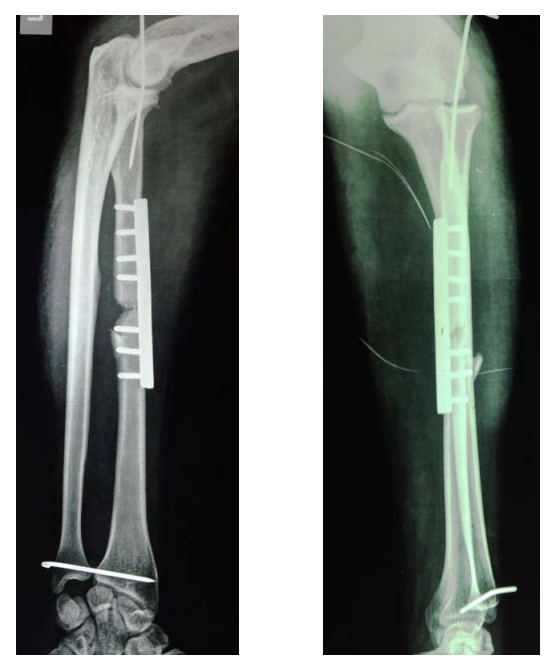

Figure 6. Post-operative X-rays. 
At 8 weeks postoperatively the person regained normal range of movement of the wrist and up to 100 degrees of elbow flexion, however the pronation-supination movement was still restricted and short of 15 to 20 degrees to full range as compared to the opposite limb. After four months of the surgery the person nearly regained his normal range of movement and the fracture also healed well.

\section{Discussion}

Association of dislocation of radio-ulnar joints along with fracture of single forearm bone was noticed by orthopaedic fraternity long before the introduction of the X-rays. Monteggia described the peculiar association of ulnar fractures with dislocation of proximal radio-ulnar joint in 1814 [2]. However this fracture was made famous by successive studies by various authors like Evans in 1948 and Penrose in 1951 [7]. Bado et al. systemically studied the fracture and classified it in his landmark paper on 1967 [5]. Galeazzi fracture dislocation was described later on in 1934 and found to complement the Monteggia fracture dislocation wherein the fracture shaft of the radius is associated with dislocation of the distal radio-ulnar joint. Both the fracture dislocation necessitated anatomical reduction of the fracture and relocation of the joint to regain the normal forearm functions notably the supination-pronation movements. That is why they were termed "fracture of necessity" by Campbell. Hughston further established the idea of open reduction and internal fixation in Galeazzi fracture [8].

Disruption of the interosseous membrane along with fracture of the forearm bones needs special mention. Essex-Lopresti described a special fracture type where radial head fracture is associated with interosseous membrane disruption [9]. This fracture should be anatomically reduced and fixed or alternatively the radial had can be replaced by silastic implants. The interosseous membrane heals conservatively in 6 to 8 weeks time and excision of the radial head if required should be deffered by this period; otherwise the radius migrates proximally causing subluxation of the distal radio-ulnar joint.

Regarding the mechanism of these fracture patterns there are controversies. Usually the Galeazzi fractures are produced by fall on an outstretched pronated forearm [10]. Another mechanism is considerable axial load with hyperextended wrist and pronated forearm [11]. Direct blow to dorsoradial aspect of forearm is explained to be another mechanism [8].

Monteggia fracture dislocation also occurs on fall over an outstretched hand but with hyperpronated forearm but it also has many other mechanisms [5] [12]. Bado extensively described these mechanisms associated with different classes of Monteggia fractures. The mechanisms include direct blow over ulnar shaft, hyperpronation during fall, hyperextension of the elbow, axial force on semiflexed elbow and varus force on extended elbow.

In Galeazzi fracture the DRUJ demands special attention. After anatomical restoration of the length of the radius the stability of the DRUJ should be assessed. If it is found stable then the forearm should be immobilized in supination for 4 - 6 weeks [11]. Unstable DRUJ may require open reduction and internal fixation along with repair of TFCC or fixation of ulnar styloid. Alternately percutaneous pinning can be done fixing the DRUJ and ulnar styloid.

Many variant of these fractures are described [4] [12] [13]. Rarely both the fracture pattern can exist in the same forearm [14]-[17]. The mechanism of injury in such types is not clearly defined.

This particular case also may be due to fall on outstretched hand but with considerable axial force and the exact rotational position of the forearm is uncertain. The elbow might sustain some varus force combined with rotation causing radial head to dislocate from its position. It was also associated with gross injury to interosseous membrane. This was assumed from the gross swelling of the forearm from proximal to the distal end and later confirmed during open reduction of the fracture.

The rareness of this case and the relative dearth of literature in this matter compelled us to direct our treatment towards normal protocol of Monteggia and Galeazzi fracture dislocation management. The stabilizing K-wires were removed in 6 weeks and physiotherapy started.

From this case we can draw an inference that many new pattern of injury combination is possible in forearm fracture dislocations. Careful evaluation of the patient supplemented by good radiographs of the joints have important role in detecting such patterns and thus help in adequate treatment.

\section{Conclusion}

There are many variants to classical Monteggia and Galeazzi fractures which are later added by subsequent authors and now these variants are well studied and well recognized. This particular fracture resulting from indirect 
violence may add a new possible variant of this complex group of fractures of forearm. However, another few cases are to be added to the literature to study correctly the exact biomechanics of this variant.

\section{Consent}

Informed consent was taken for this work.

\section{Conflict of Interest}

The authors declare that they have no conflict of interests.

\section{References}

[1] Galeazzi, R. (1934) Di una particolare sindrome traumatic dello scheletro dell’ avambraccio [Italian]. Atti Mem Soc Lombardi Chir, 2, 12-15.

[2] Monteggia, G.B. (1814) Instituzioni Chirrugiche. Vol. 5, Maspero, Milan.

[3] Beutel, B.G. (2012) Monteggia Fractures in Pediatric and Adult Populations. Orthopedics, 35, 138-144. http://dx.doi.org/10.3928/01477447-20120123-32

[4] Atesok, K.I., Jupiter, J.B. and Weiss, A.P. (2011) Galeazzi Fracture. Journal of the American Academy of Orthopaedic Surgeons, 19, 623-633.

[5] Bado, J.L. (1967) The Monteggia Lesion. Clinical Orthopaedics and Related Research, 50, 71-86. http://dx.doi.org/10.1097/00003086-196701000-00008

[6] Giannoulis, F.S. and Sotereanos, D.G. (2007) Galeazzi Fractures and Dislocations. Hand Clinics, 23, $153-163$. http://dx.doi.org/10.1016/j.hcl.2007.03.004

[7] (2011) Fractures of the Shaft of the Radius and Ulna. In: Richards, R.R. and Corley, F.G., Eds., Rockwood and Greens, Fractures in Adults, Lippincott-Raven, Philadelphia.

[8] Hughston, J.C. (1957) Fracture of the Distal Radial Shaft; Mistakes in Management. Journal of Bone and Joint Surgery, 39A, 249-264.

[9] Essex-Lopresti, P. (1951) Fractures of the Radial Head with Distal Radioulnar Dislocation: Report of Two Cases. Journal of Bone and Joint Surgery, 33B, 244-247.

[10] Mikic, Z.D. (1975) Galeazzi Fracture-Dislocations. Journal of Bone and Joint Surgery, 57, 1071-1080.

[11] Aulicino, P.L. and Siegel, J.L. (1991) Acute Injuries of the Distal Radioulnar Joint. Hand Clinics, 7, $283-293$.

[12] Boyd, H.B. and Boals, J.C. (1969) The Monteggia Lesion. A Review of 159 Cases. Clinical Orthopaedics and Related Research, 66, 94-100.

[13] Sebastin, S.J. and Chung, K.C. (2010) A Historical Report on Riccardo Galeazzi and the Management of Galeazzi Fractures. Journal of Hand Surgery, 35, 1870-1877. http://dx.doi.org/10.1016/j.jhsa.2010.08.032

[14] Mann, C.J., Jeer, P., Housden, P. and Hyde, I.D. (2000) Combined Galeazzi and Monteggia Forearm Fractures. Journal of the Royal Society of Medicine, 93, 144-145.

[15] Maeda, H.Y., Doi, R. and Omori, O. (2003) Combined Monteggia and Galeazzi Fractures in a Child: A Case Report and Review of the Literature. Journal of Orthopaedic Trauma, 17, 128-131. http://dx.doi.org/10.1097/00005131-200302000-00010

[16] Boopalan, P.R.J.V.C., Titus, V.T.K., et al. (2007) Ipsilateral Galeazzi and Monteggia Fracture. Injury Extra, 38, 308311. http://dx.doi.org/10.1016/j.injury.2006.11.024

[17] Jafari, D., Taheri, H., Shariatzade, H., Mazhar, F.N., Jalili, A. and Ghahramani, M.H. (2012) Bilateral Combined Monteggia and Galeazzi Fractures: A Case Report. Medical Journal of Islamic Republic of Iran, 26, 41-44. 
Scientific Research Publishing (SCIRP) is one of the largest Open Access journal publishers. It is currently publishing more than 200 open access, online, peer-reviewed journals covering a wide range of academic disciplines. SCIRP serves the worldwide academic communities and contributes to the progress and application of science with its publication.

Other selected journals from SCIRP are listed as below. Submit your manuscript to us via either submit@scirp.org or Online Submission Portal.
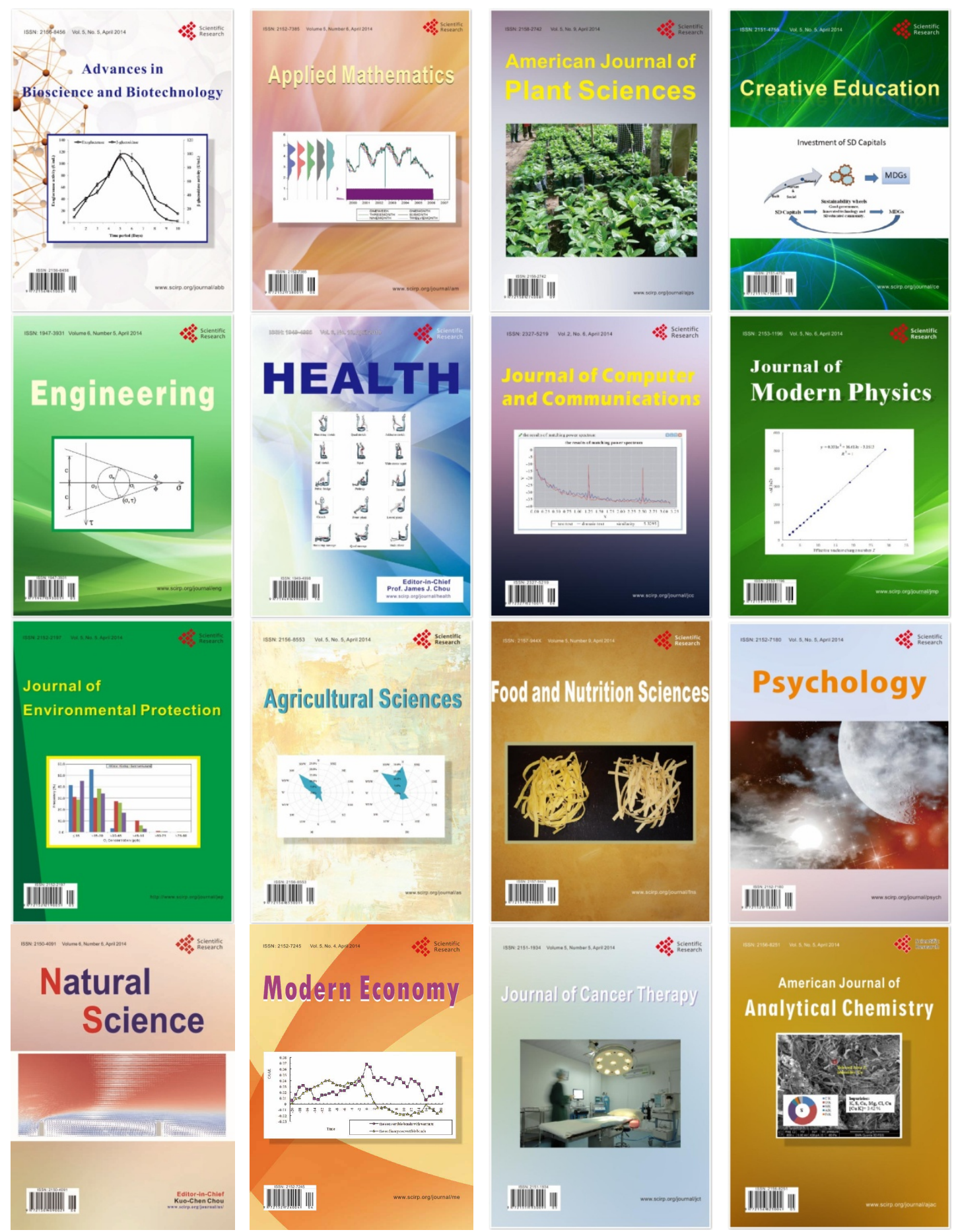